\title{
DEVELOPMENT OF REAL-TIME PCR ASSAY FOR DETECTION OF Anaplasma marginale
}

\section{S.N. KOVAL'CHUK'ㄹ, G.Yu. KOSOVSKII' ${ }^{1}$, A.V. ARKHIPOV'1, T.T. GLAZKO1, 2 , V.I. GLAZKO1, 2}

\begin{abstract}
${ }^{1}$ Center for Experimental Embryology and Reproductive Biotechnology, Federal Agency of Scientific Organizations, 12/4, ul. Kostyakova, Moscow, 127422 Russia, e-mail s.n.kovalchuk@mail.ru, gkosovsky@mail.ru, batler51@yandex.ru, tglazko@rambler.ru, vglazko@yahoo.com, info-ceerb@mail.ru

${ }^{2}$ K.A. Timiryazev Russian State Agrarian University-Moscow Agrarian Academy, 49, ul. Timiryazevskaya, Moscow, 127550 Russia

Received August 14, 2015
\end{abstract}

\section{Abstract}

Anaplasma marginale is a rickettsial pathogen responsible for bovine anaplosmosis, the acute disease in cattle herds which is associated with anemia, fever, rapid loss of milk production and weight, abortion, and, in some cases, death of the infected cattle. Anaplasma marginale is transmitted by ticks and biting insects. Diagnosis of bovine anaplasmosis is made by microscopic examination of blood smears stained with Giemsa stain, but this method is not useful to detect presymptomatic animals. Several serological tests have used extensively for epidemiological studies, but they do not discriminate between different Anaplasma species. A real-time polymerase chain reaction (PCR) combines high specificity with accurate measurement of DNA copy number and allows quantification of the targeted pathogen DNA. The goal of this study was to develop a real-time PCR assay for differential detection of $A$. marginale in the blood of cattle. The single-copy gene $m s p 4$ was chosen as a target DNA for PCR. Msp4 is a dominant immune protein of outer membrane of all Anaplasma knowen to date. The primers for phylogenetic analysis in $A$. marginale based on msp4 were reported earlier by J. de la Fuente et al. (2001), but they were not species-specific. The analysis of msp4 gene sequence of different $A$. marginale isolates and closely related species, including $A$. ovis, revealed species-specific areas, which were used for design of primers and TaqMan probe (MSP4-F 5'-CATGAGTCACGAAGTGGCT-3' and MSP4-R 5'-GGCACACT-CACATCAATC-3', MSP4-probe 5'-(Cy5)-AAGGGGGAGTAATGGGAGGTAGCT-3') for amplification and detection of $177 \mathrm{bp}$ fragment of msp4 gene by a real time PCR. In the amplified nucleotide sequences a 99 to $100 \%$ homology to msp4 fragments was found in different isolates of $A$. marginale. To assess analytical sensitivity of our PCR test, we used pGEM-msp4, a constructed recombinant plasmid with $177 \mathrm{bp}$ fragment of $m s p 4$ gene, diluted to obtain samples with $10^{0-10^{7}} \mathrm{msp} 4$ copies. It was shown that the assay was able to detect as few as $10^{2}$ of $A$. marginale msp4 gene in the analyzed DNA sample. Analytical specificity of the developed primers and the MSP4-probe was proved in tests with DNA of sheep naturally infected by $A$. ovis, and also DNA isolated from cows with Sanguibacter keddieii, Propionibacterium acnes and Pseudomonas aeruginosa infection pre-detected by sequencing. In these samples no increased fluorescence characteristic of probes from animals infected by $A$. marginale was observed with no PCR products identified. Thus, the method specificity allowed to differentiate $A$. marginale and $A$. ovis. The developed method of $A$. marginale identification on the basis on amplification and detection of the msp4 gene fragment using a real time PCR differed from known analogues with high sensitivity, rapidity and opportunity of quantitative evaluation of the bacterial load. The developed method could be used for rapid differential detection and quantification of $A$. marginale in blood samples from infected cattle for confirmation of anaplasmosis and epidemiological studies.

Keywords: Anaplasma marginale, msp4 gene, cattle, diagnostics, a real-time PCR.

Bovine anaplasmosis is a vector-borne infectious disease caused by genus Anaplasma (order Rickettsiales, family Anaplasmatacea) rickettsia. Bovine anaplasmosis is widespread throughout the world and causes significant economic losses due to the reduced milk and meat productivity of cattle and the damages resulted from the loss of young animals and animal deaths. Anaplasma marginale, an obligate intracellular erythrocyte damaging parasite, is a rickettsial pathogen responsi- 
ble for bovine anaplosmosis. Cattle co-infection with $A$. ovis anaplasma has also been described [1]. Infected animals are the source of anaplasmosis, and the pathogen is transmitted by about 20 species of ticks and blood-sucking insects [2, 3]. In addition, mechanical transmission of pathogen from infected animals to healthy ones is possible through contaminated zootechnical instruments.

Bovine anaplasmosis caused by $A$. marginale has been registered in many tropical and substropical countries, throughout USA and Canada, and in some European countries, mainly of the Mediterranean [4, 5]. This disease has been registered in Ukraine, Belarus, Moldova, Kazakhstan, and in the countries of Central Asia and the Caucasus. According to the Russian Federation veterinary reports on anaplasmosis, the Central, Northwestern and Volga Federal Districts are insecure [6].

Currently, microscopic and serological methods are used for the diagnosis of anaplasmosis, but their sensitivity and specificity are insufficient. The results of microscopic examination of blood smears are unreliable, especially in the early stages of infection and in cases of diseases accompanied by severe anemia [7, 8]. Serological methods based on the use of antibodies against anaplasmosis pathogen antigens are insufficiently sensitive and do not discriminate between $A$. marginale and other Anaplasma species [9-11]. The advantage of PCR diagnostics is its high sensitivity and specificity. It allows to detect pathogens in the earliest stages of the disease, including the latent phase, and to reliably differentiate anaplasmosis from a series of pathologies with similar clinical manifestations. According to the recommendations of the World Organisation for Animal Health (OIE) (http://www.oie.int/en/international-standardsetting/terrestrial-manual/access-online/), A. marginale PCR diagnostics should be performed prior to each movement of the animal to a new location, and to confirm the diagnosis. Various PCR methods to detect $A$. marginale have been described [12-22], but none of them has been fully validated.

The purpose of this study was to develop a real-time PCR assay to identify Anaplasma marginale in the blood of cattle.

Technique. For the selection of primers, gene sequences available in the GenBank database (http://www.ncbi.nlm.nih.gov/genbank/) were used (msp4 of various $A$. marginale isolates, as well as $A$. centrale, $A$. ovis and A. phagocytophilum). Conservative msp4 sites which may serve as primers and the probe were identified using the resources of ClustalW2 server at open access (http://www.ebi.ac.uk/Tools/msa/clustalw2/). Primer and probe species specificity was evaluated by the BLASTN (http://blast.ncbi.nlm.nih.gov/Blast.cgi) algorithm.

The analyzed DNA samples were isolated from whole blood of naturally infected animals (bovine cattle infected with $A$. marginale, as well as with Sanguibacter keddieii, Propionibacterium acnes, and Pseudomonas aeruginosa, and sheep infected with $A$. ovis). For this purpose, the Sorb-M kit (Sintol, Russia) was used according to manufacturer's recommendations.

The amplification was performed in real-time PCR in a mixture of $10 \mu \mathrm{l}$ LightCycler ${ }^{\circledR} 480$ Probes Master PCR reagent (Roche, Switzerland); MSP4-F 5'- CATGAGTCACGAAGTGGCT-3' primer $(0.5 \mu \mathrm{M})$, MSP4-R 5'GGCACACTCACATCAATC-3' primer $(0.5 \mu \mathrm{M})$; MSP4-probe 5'-(Cy5)-AAGGGGGAGTAATGGGAGGTAGCT-3' fluorescently labeled probe $(0.1 \mu \mathrm{M})$; $3 \mu \mathrm{l}$ of DNA; total reaction volume was $20 \mu \mathrm{l}$. PCR was performed using a LightCycler 96 instrument (Roche, Switzerland) under the following conditions: initial denaturation for $2 \mathrm{~min}$ at $95{ }^{\circ} \mathrm{C} ; 45$ cycles of $15 \mathrm{sec}$ at $95{ }^{\circ} \mathrm{C}, 15 \mathrm{sec}$ at $58{ }^{\circ} \mathrm{C}, 15 \mathrm{sec}$ at $72{ }^{\circ} \mathrm{C}$. The fluorescence signal was recorded for the $\mathrm{Cy} 5$ 
channel. PCR results were also assessed by electrophoresis in $2 \%$ agarose gel.

The msp4 gene fragment of $177 \mathrm{bp}$ produced in PCR was purified using the GeneJET PCR Purification Kit (Life Technologies, USA), ligated into pGEM-T vector (Promega, USA) and cloned in Escherichia coli DH5 cells. To identify the colonies of transformants containing the pGEM-msp4 plasmid, PCR was performed using a pair of standard primers for M13 sequencing (SibEnzyme, Russia) with subsequent analysis of the amplification products by electrophoresis in $2 \%$ agarose gel.

Target colonies were incubated overnight at $37{ }^{\circ} \mathrm{C}$ in $2 \mathrm{ml}$ of liquid LB medium, containing ampicillin at $100 \mu \mathrm{g} / \mathrm{ml}$ concentration. To purify plasmid DNA, GeneJET Miniprep Kit (Thermo Fisher Scientific, CШA) was used. Plasmid DNA concentration was estimated using PicoGreen ${ }^{\circledR}$ dsDNA Assay Kit (Thermo Fisher Scientific, USA) with a QuantiFluor-ST fluorimeter (Promega, USA). Sequencing of the resulting pGEM-msp4 plasmids was performed according to the Sanger method with ABI Prism Big Dye Terminator 3.1 Cycle Sequencing Kit (Applied Biosystems, USA) and an Applied Biosystems 3130 genetic analyzer (Life Technologies, USA). To determine PCR analytical sensitivity, a series of 10-fold dilutions of the pGEM-msp4 plasmid was made and the samples containing $10^{0-} 10^{7} \mathrm{msp} 4$ gene copies were obtained. Estimation of PCR analytical sensitivity was performed in triplicate.

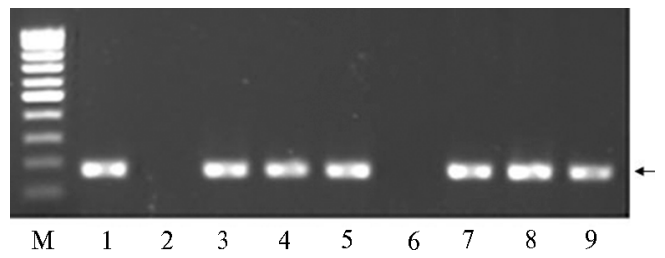

Fig. 1. Electrophoretic separation of DNA produced in PCR using the original primers (MSP4-F and MSP4-R) and DNA extracted from the blood of infected (1, 3-5, 7-9) and uninfected with Anaplasma marginale $(2,6)$ cows: $M-$ DNA size marker (100-1000 bp, Dialat Ltd., Russia). An arrow marks the fragment of $177 \mathrm{bp}$.

Results. In this study, the primers and probe for the amplification and detection of $A$. marginale msp4 (major surface protein 4) gene fragment for real-time PCR were designed. Msp4 is an immunodominant outer membrane protein found in all currently known genus Anaplasma rickettsia [5, 23]. According to wholegenome sequencing, msp4 is presented by one copy only in $A$. marginale [24]. The msp4-based primers for phylogenetic analysis of $A$. marginale have been proposed earlier by J. de la Fuente et al. [13], but they are not species specific for this anaplasma since they are $100 \%$ identical to the portions of A. ovis msp4 gene, whereby they can not be used to differentiate these two pathogens. The msp4-based primers have also been proposed for the differential detection of $A$. marginale and $A$. ovis by classic PCR with the identification of amplification products by electrophoresis in agarose gel [17]. The real-time PCR advantage compared to classical PCR is the registration of DNA accumulation directly during PCR, i.e. the PCR result detection as an additional analysis phase is absent. This reduces the time of study considerably, while the combination of primers and species specific fluorescently labeled probe improves the reliability of correct pathogen identification.

The selected MSP4-F and MSP4-R primers were used for PCR in which bovine DNA from $A$. marginale infected animals served as a template, that was confirmed by the results of earlier genome sequencing of bovine genome fragments [25], and PCR with AmargMSP4Fw 5'-CTGAAGGGGGAGTAATGGG-3' and AmargMSP4Rev 5'-GGTAATAGCTGCCAGAGATTCC3' primers for msp4 in A. marginale, according to A. Torina et al. [17] was conducted. As a result of PCR with the MSP4-F and MSP4-R primers designed by 
us (Fig. 1), DNA fragments of $177 \mathrm{bp}$ were produced and sequenced.

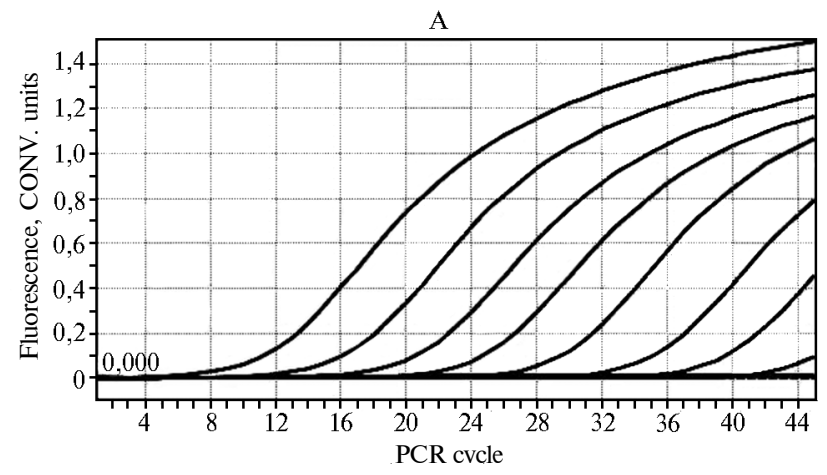

B

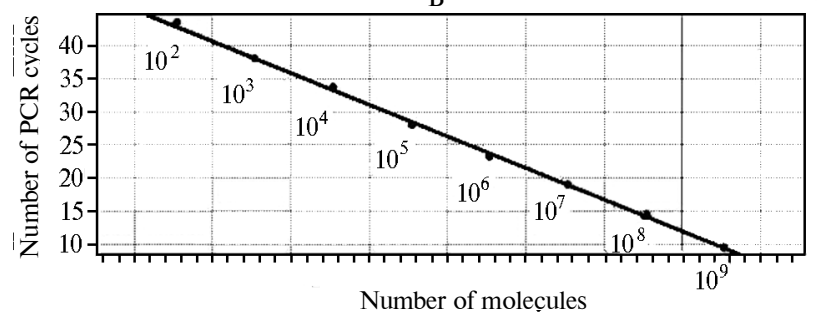

rease in fluorescence was observed.

To test the specificity of MSP4-F and MSP4-R primers and MSP4 probe, DNA samples from sheep infected with $A$. ovis rickettsia were used, which was found as a result of PCR with AovisMSP4Fw 5'-TGAAGGGAGCGGGGTCATGGG-3' and AovisMSP4Rev 5'-GAGTAATTGCAGCCAGGGACTCT-3' primers for A. ovis msp4 [17], as well as bovine DNA samples which according to sequencing [25] contained Sanguibacter keddieii, Propionibacterium acnes and Pseudomonas aeruginosa bacterial DNA. Unlike the samples from $A$. marginale infected animals, no increases in fluorescence were observed in these DNA samples in real-time PCR and no PCR products were identified under electrophoretic separation indicating the species specificity of primers and probe.

The pGEM-msp4 plasmid with the msp4 gene fragment of $177 \mathrm{bp}$ (standard) was constructed in estimating PCR analytical sensitivity, and the samples containing $10^{0-} 10^{7}$ copies of msp4 gene fragment were obtained by 10 -fold serial dilutions of the standard. The results of PCR with these samples as template and combination of the primers and the probe developed by us demonstrated that the method sensitivity makes it possible to detect $10^{2}$ and more msp4 copies in the test sample volume (Fig. 2), that is, given the single copy of this gene [24], from 100 molecules of $A$. marginale DNA.

It should be noted that our method of $A$. marginale detection differs from the existing analogues $[13,17]$ due to high specificity, rapidity and the possibility of quantifying bacterial load.

Thus, we have developed a pair of primers and a probe for the msp4 gene for differential detection of Anaplasma marginale rickettsia in bovine blood by real-time PCR. This method sensitivity makes it possible to detect from $10^{2}$ msp 4 copies in the $A$. marginale DNA sample volume, and its specificity is sufficient to reliably differentiate $A$. marginale and $A$. ovis. So the suggested method is highly specific unlike those described in publications. Moreover, it makes it possible to quantify the bacterial load, while the procedure requires less time. Therefore, it can be used, if necessary, for the 
prompt differential detection and quantification of $A$. marginale in the blood samples of infected cattle to confirm the diagnosis and perform epidemiological monitoring of anaplasmosis.

\section{REFERENCES}

1. Ko c a n K.M., de la Fuente J., B lou in E.F., Coetze e J.F., Ew ing S.A. The natural history of Anaplasma marginale. Vet. Parasitol., 2010, 167: 95-107 (doi: 10.1016/j.vetpar.2009.09.012).

2. Kocan K.M., d e la Fuente J., Blouin E.F., Garcia-Garcia J.C. Anaplasma marginale (Rickettsiales: Anaplasmataceae): recent advances in defining hostpathogen adaptations of a tick-borne rickettsia. Parasitology, 2004, 129: 285-300 (doi: 10.1017/S0031182003004700).

3. S coles G.A., B roce A.B., Lys y k T.J., Pa $1 \mathrm{me} \mathrm{r} \mathrm{G.H.} \mathrm{Relative} \mathrm{efficiency} \mathrm{of} \mathrm{biological}$ transmission of Anaplasma marginale (Rickettsiales: Anaplasmataceae) by Dermacentor andersoni (Acari: Ixodidae) compared with mechanical transmission by Stomoxys calcitrans (Diptera: Muscidae). J. Med. Entomol., 2005, 42: 668-675 (doi: 10.1093/jmedent/42.4.668).

4. Guglielmone A.A. Epidemiology of babesiosis and anaplasmosis in South and Central America. Vet. Parasitol., 1995, 57: 109-119.

5. de la Fuente J., Lew A., Lutz H., Meli M.L., Hofmann-Lehmann R., Shkap V., Molad T. Genetic diversity of Anaplasma species major surface proteins and implications for anaplasmosis serodiagnosis and vaccine development. Anim. Health Res., 2005, 6: 75-89 (doi: 10.1079/AHR2005104).

6. Gulyu ki n M.I., Z ab lotski i V.T., B e li m e n k o V.V. Rossiiskii veterinarnyi zhurnal SKHZH, 2013, 2: 36-40.

7. Noaman V., Shayan P. Comparison of Microscopy and PCR-RFLP for detection of Anaplasma marginale in carrier cattle. Iran. J. Microbiol., 2010, 2(2): 89-94.

8. P o t g i e t e r F.T., S t o $1 \mathrm{ts} \mathrm{z}$ W.H. Anaplasmosis. In: Infectious diseases of livestock with special reference to Southern Africa. J.A.W. Coetzer, G.R. Thompson, R.C. Tustin (eds.). Oxford University Press, Cape Town, South Africa, 1994.

9. Dreher U.M., Fuente J., Hofmann-Lehmann R., Meli M.L., Pusterla N., Kocan K.M., Woldehiwet Z., Braun U., Regula G., Staerk K.D., Lutz H. Serologic crossreactivity between Anaplasma marginale and Anaplasma phagocytophilum. Clin. Diagn. Lab. Immunol., 2005, 12: 1177-1183 (doi: 10.1128/CDLI.12.10.1177-1183.2005).

10. Al-Adhami B., Scandrett W.B., Lovanov V.A., Gajadhar A.A. Serological cross reactivity between Anaplasma marginale and Ehrlichia species in naturally and experimentally infected cattle. J. Vet. Diagn. Invest., 2011, 23: 1181-1188 (doi: 10.1177/1040638711425593).

11. Strik N.I., Alle ma $n$ A.R., B a rbet A.F., S orenso $n$ H.L., Wa m s ley H.L., Gaschen F.P., Luckschander N., Wong S., Chu F., Foley J.E., Bjo e rsdorff A., S tue n S., Know les D.P. Characterization of Anaplasma phagocytophilum major surface protein 5 and the extent of its cross-reactivity with $A$. marginale. Clin. Vaccine Immunol., 2007, 14: 262-268 (doi: 10.1128/CVI.00320-06).

12. Torioni de Echaide S., Knowles D.P., McGuire T., Palmer G.H., Sua re z C.E., M c E lw a i n T.F. Detection of cattle naturally infected with Anaplasma marginale in a region of endemicity by nested PCR and a competitive Enzyme-Linked Immunosorbent Assay using recombinant major surface protein 5. J. Clin. Microbiol., 1998, 36: 777-782.

13. d e la Fuente J., V a n D e n B u s c he R.A., Ko c a n K.M. Molecular phylogeny and biogeography of North American isolates of Anaplasma marginale (Rickettsiaceae: Ehrlichieae). Vet. Parasitol., 2001, 97: 65-76 (doi: 10.1016/S0304-4017(01)00378-8).

14. Care 11 i G., D e caro N., Lorusso A., Elia G., Lorus o E., Mari V., $\mathrm{Ceci}$ L., Bu o navogli a C. Detection and quantification of Anaplasma marginale DNA in blood samples of cattle by real-time PCR. Vet. Microbiol., 2007, 124: 107-114 (doi: 10.1016/j.vetmic.2007.03.022).

15. Fyumagwa R.D., S i m m le r P., M eli M.L., Hoare R., Hofmann-Lehmann R., $\mathrm{Lu}$ z $\mathrm{H}$. Prevalence of Anaplasma marginale in different tick species from Ngorongoro Crater, Tanzania. Vet. Parasitol., 2009, 161(1-2): 154-157 (doi: 10.1016/j.vetpar.2008.12.018).

16. Picoloto G., Li ma R.F., O legário L.A.O., C a rvalho C.M.E., Lace rda A.C.R., To más W.M., B orges P.A.L., P e 11 e gri n A.O., Madruga C.R. Real-time polymerase chain reaction to diagnose Anaplasma marginale in cattle and deer (Ozotoceros bezoarticus leucogaster) of the Brazilian Pantanal. Brazilian Journal of Veterinary Parasitology, 2010, 19(3): 186-188 (doi: 10.1590/S1984-29612010000300012).

17. Torina A., Agnone A., B 1 a nda V., Alongi A., D'Agostino R., Cara c a p p a S., M a ri no A.M., Di M a r co V., d e la Fue nte J. Development and validation of two PCR tests for the detection of and differentiation between Anaplasma ovis and Anaplasma marginale. Ticks and Tick-borne Diseases, 2012, 3(5-6): 283-287 (doi: 
10.1016/j.ttbdis.2012.10.033).

18. Reinbold J.B., Coetzee J.F., Sirigireddy K.R., Ganta R.R. Detection of Anaplasma marginale and A. phagocytophilum in bovine peripheral blood samples by duplex real-time reverse transcriptase PCR assay. J. Clin. Microbiol., 2010, 48(7): 2424-2432 (doi: 10.1128/JCM.02405-09).

19. Molad T., Mazuz M.L., Fleiderovitz L., Fish L., Savitsky I., Krigel Y., Leibovitz B., Molloy J., Jongejan F., Shkap V. Molecular and serological detection of $A$. centrale- and $A$. marginale-infected cattle grazing within an endemic area. Vet. Microbiol., 2006, 113: 55-62 (doi: 10.1016/j.vetmic.2005.10.026).

20. Bilgiç H.B., Karagenç T., S i muunza M., Shiels B., Tait A., Eren H., Weir W. Development of multiplex PCR assay for simultaneous detection of Theileria annulata, Babesia bovis and Anaplasma marginale in cattle. Exp. Parasitol., 2013, 133(2): 222-229 (doi: 10.1016/j.exppara.2012.11.005).

21. Lew A.E., Bock R.E., Minchin C.M., Masaka S. A msplalpha polymerase chain reaction assay for specific detection and differentiation of Anaplasma marginale isolates. Vet. Microbiol., 2002, 86: 325-333 (doi: 10.1016/S0378-1135(02)00017-2).

22. Ybañez A.P., Sivakumar T., Ybañez R.H.D., Ratilla J.C., Perez Z.O., Gabotero S.R., Hakimi H., Kawazu S., Matsumoto K., Yokoyama N., Ino$\mathrm{k} \mathrm{u} \mathrm{m} \mathrm{a} \mathrm{H.} \mathrm{First} \mathrm{molecular} \mathrm{characterization} \mathrm{of} \mathrm{Anaplasma} \mathrm{marginale} \mathrm{in} \mathrm{cattle} \mathrm{and} \mathrm{Rhipicephalus}$ (Boophilus) microplus ticks in Cebu, Philippines. J. Vet. Med. Sci., 2013, 75: 27-36 (doi: 10.1292/jvms.12-0268).

23. Vidotto M.C., McGuire T.C., McElwain T.F., Palmer G.H., Knowles D.P. Jr. Intermolecular relationships of major surface proteins of Anaplasma marginale. Infect. Immunol., 1994, 62(7): 2940-2946.

24. Brayton K.A., Kappmeyer L.S., Herndon D.R., Dark M.J., Tibbals D.L., Palmer G.H., McGuire T.C., Knowles D.P. Jr. Complete genome sequencing of Anaplasma marginale reveals that the surface is skewed to two superfamilies of outer membrane proteins. PNAS USA, 2005, 102(3): 844-849 (doi: 10.1073/pnas.0406656102).

25. Glazko V.I., Kosovski G.Yu., Koval'chuk S.N., Arkhipov A.V., Petrova I.O., Dedovich G.O., Glazko T.T. Innovatsionnye tekhnologii v meditsine, 2014, 2(03): 63-79. 